\title{
Modelling of a Reverse Layer of Fire-Induced Smoke in a Tunnel
}

\author{
A. GUELZIM, J. M. SOUIL and J. P. VANTELON \\ Laboratoire de Chimie Physique de la Combustion \\ Ecole Nationale Supérieure de Mécanique et d'Aérotechnique \\ Site du Futuroscope - BP 109 \\ Chasseneuil du Poitou - 86960 Futuroscope Cedex - France
}

DOAN KIM SON

Laboratoire de Thermique

Ecole Nationale Supérieure de Mécanique et d'Aérotechnique

Site du Futuroscope - BP 109

Chasseneuil du Poitou - 86960 Futuroscope Cedex - France

D. GABAY and D. DALLEST

Régie Autonome des Transports Parisiens

Service Logistique

124 rue du Mont Cenis, 75018 Paris, France

\begin{abstract}
The designers of tunnels must provide comfortable conditions for occupants. This necessitates particularly the development of ventilation equipments well suited for routine operation but also efficient in the case of accidental fires while at the same time offering the possibility of control.

A computer model for simulation of fire growth and smoke back flow phenomenon countering the effect of ventilation is described. It permits one to predict the length of the reverse layer under a ceiling as a function of two main parameters : ventilation speed and rate of heat release of the fire. Special attention is devoted to the description of the fire source with consideration of the interaction between flow and the chemical reaction. The validation of the model against experimental results, obtained previously on a small-scale prototype, appears satisfying. An application to the Paris metro tunnels is also presented. The validity of the predictive results is infered from the similarity between small-scale and real situation based on a scaling procedure.
\end{abstract}

KEYWORDS : Fire hazards in tunnels - Fire modelling - Smoke movement modelling 


\section{NOTATION LIST}

C Efficiency factor quantifying the completeness of the combustion

$\mathrm{C}_{\mathrm{p}}$ Specific heat J.kg-1.K-1

$\mathrm{e}$ Thickness of gas layer $\mathrm{m}$

$\mathrm{B}_{\mathrm{b}} \quad$ Entrainment coefficient

g Gravitational acceleration $\mathrm{m} . \mathrm{s}^{-2}$

h Convective heat transfer coefficient W. $m^{-2} \cdot K^{-1}$

$\Delta \mathrm{H}_{\mathrm{c}} \quad$ Heat of combustion of fuel J.kg-1

$\mathrm{k}$ Turbulent kinetic energy $\mathrm{m}^{2} \cdot \mathrm{s}^{-2}$

$k_{v} \quad$ Velocity factor defined by $\mathrm{Eq}(11)$

$\mathrm{me}_{\mathrm{e}}$ Air entrainment mass flow rate of a flame length unit $\mathrm{kg} \cdot \mathrm{m}^{-1} . \mathrm{s}^{-1}$

p Pressure N.m-2

$\mathrm{P}_{\mathbf{i}} \quad$ Production rate of species $\mathbf{i} \mathbf{s}^{-1}$

$q^{\prime} r \quad$ Radiation of a flame length unit W. $m^{-1}$

$q^{\prime \prime} r_{c}$ Radiative heat flux to the ceiling $W \cdot m^{-2}$

$Q$ Volumetric heat release rate $W \cdot m^{-3}$

$\mathbf{r}$ Plume radius $m$

$s$ Distance along the plume trajectory $m$

$T$ Temperature $K$

$v$ Plume velocity $\mathrm{m} . \mathrm{s}^{-1}$

$V_{\infty} \quad$ Ventilation velocity m.s -1

$x$ Distance along the ceiling $m$

$Y_{i} \quad$ Mass fraction of species $\mathbf{i}$

$\mathrm{z}$ Distance measured normal to the ceiling $\mathrm{m}$

Greek

a Tangential entrainment constant

$\beta \quad$ Normal entrainment constant

$\varepsilon$ Rate of dissipation of turbulent kinetic energy $\mathrm{m}^{2} . \mathrm{s}^{-3}$

$\theta \quad$ Inclination of plume to horizontal

$\lambda$ Thermal conductivity of the ceiling material W. $\mathrm{m}^{-1} \cdot \mathrm{K}^{-1}$

$v \quad$ Mass stoichiometric air to fuel ratio

$\rho$ Density $\mathrm{kg} \cdot \mathrm{m}^{-3}$

L Shear stress $\mathrm{kg} \cdot \mathrm{m}^{-1} \cdot \mathrm{s}^{-2}$

$\mathrm{X}$ Radiative fraction

Subseripts

b Backward gas layer

c Pertaining to ceiling

f Forward gas layer

F Pertaining to fuel

$i \quad$ Inner face of the ceiling

- Outer face of the ceiling or initial value

ox Pertaining to oxydant

p Pertaining to plume

s Pertaining to smoke

$\infty \quad$ Ambiant air flow

\section{INTRODUCTION}

The problem of comfort and hygiene is of major importance to the travelling public, especially in underground travel. In the course of the equipment evolution particularly, increasingly higher performance ventilation systems are used to maintain tenable conditions.

There are different types of forced tunnel ventilation : longitudinal, transverse and semitransverse. In medium and long tunnels such as the ones encountered in the metro network, the main type used is the longitudinal 
ventilation by extraction. However, the risks from accidental fires as well as the subsequent smoke movement depends largely on these applied ventilation currents. Under certain flow and power fire conditions, a reverse layer of smoke forms near the ceiling and flows against the forced ventilation flow.

Eisner and Smith (1) were the first to conduct experiments on this phenomenon and reported that backflow is the result of convective currents rising from the fire. This continues until its buoyancy is reduced by heat loss to the strata or to the air beneath. Thomas $(2)(3)$ has proposed a fundamental criterion for backflow which is that the ratio of the buoyancy head to the velocity head must be greater than unity. On the basis of this criterion, De Ris (4) analyzed fire spreading within ventilated fuel-lined ducts. Other attempts using more or less sophisticated models, particularly field models, have been developed but Hwang et al. (5) were the first to propose an effective theoretical analysis of reverse stratified flows in tunnel fires in the presence of longitudinal ventilation. They developed a two-dimensional model predicting the length of the reverse layer as a function of ventilation speed and the mass flux of the fire plume. However, their formulation of the combustion process was restricted to the simple and common assumption that the entrained air mixes with the fuel and burns to stoechiometric completion instantaneously. No attention was devoted to the interaction between the air flow and the chemical reaction in the fire.

Given the difficulty of trying to conduct large scale experiments, we developed, in an earlier work (6), a simple scale modelling procedure for laboratory scale experiments. It permitted predicting the full scale length of the reverse layers by identifying the major parameters of the system and expressing these in the form of relevant dimensionless groups which are preserved for small and fullscale systems. Nevertheless, it is also very useful to develop numerical simulation model reliable, easy to use, and with acceptable computational time. This is the objective of the following analysis.

\section{THEORETICAL APPROACH}

The description of the phenomenon is divided into three parts : modelling of the fire plume, modelling of the plume impingement on the tunnel ceiling, and modelling of the reverse layer.

\section{1/ Plume Modelling}

The problem is three-dimensional in nature. However, to facilitate the analysis, the fire plume is pictured to be pseudo two-dimensional. The model has already been described in a previous work dealing with flame radiation from pool fires tilted by wind (Guelzim et al. (7)) and, thus, only its essential features are given here. As in most previous fire analyses, we based the description on the assumption of self-similarity of the temperature, velocity and concentration profiles within the flame, and to further facilitate the solution of the problem, these profiles are taken to have "top-hat" forms. Moreover the flow is assumed to be quasi-steady. The flame is considered to be uniformly bent by the wind, the angle of tilt $\theta$ with respect to the horizontal being a function of the air moventent intensity $V_{\infty}$, assumed also quasi-steady, horizontal and spatially uniform. This assumption of uniform bending appears to be justified on the basis of common observation evidence. The combustible surface is assumed to be circular of radius $r$. The motion of the mixture of gases flowing within the boundaries of the inclined plume generated is governed by the following conservation equations incorporating an exothermic rapid chemical reaction and the radiative loss to the environment (see Fig. 1). 


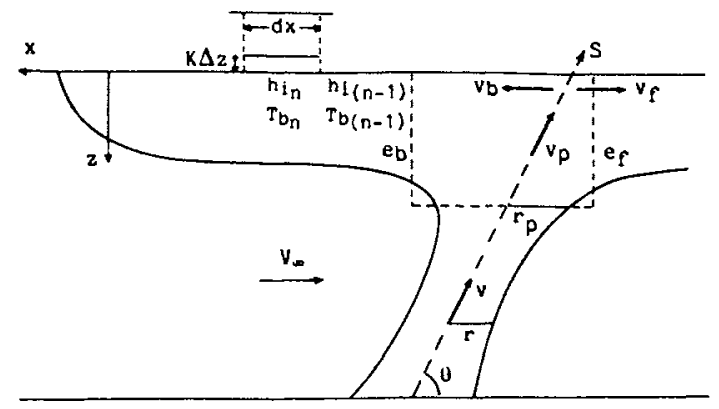

FIGURE 1 Schematic of the reverse layer with notation

- Conservation of mass :

$\frac{d}{d s}\left(\rho r^{2} v\right)=\frac{m_{e}}{\mathrm{II}}$

- Conservation of vertical momentum :

$\sin \theta \frac{d}{d s}\left(\rho r^{2} v^{2}\right)=g r^{2}\left(\rho_{\infty}-\rho\right)$

- Conservation of horizontal momentum :

$$
\cos \theta \frac{d}{d s}\left(\rho r^{2} v^{2}\right)=v_{\infty} \frac{d}{d s}\left(\rho r^{2} v\right)
$$

- Conservation of energy :

$$
\frac{d}{d s}\left(u r^{2} \rho C_{p}\left(T-T_{\infty}\right)\right)=Q r^{2}-q_{r}
$$

- Conservation of species i :

$$
\frac{d}{d s}\left(\rho r^{2} v Y_{i}\right)=\frac{m_{e}}{\pi} Y_{i_{\infty}}+\rho r^{2} P_{i}
$$

(A complete list of symbols is given in the nomenclature)

As in most analysis of turbulent free-shear flow, it is assumed that the plume's dynamic is dominated by the turbulence generated internally as a result of the motion relative to the surroundings. The basic entrainment hypothesis that assumes that the air is entrained into the flame at rates proportional to the magnitude of the velocity difference between the plume and the ambiant air is applied to the uniformely bent flame in the directions parallel and normal to the plume $(8)(9)$. Then, the plume entrainment rate assumes the following form: 


$$
m_{e}=2 n \rho_{\infty} r\left(\rho / \rho_{\infty}\right)^{1 / 2}\left[a\left(v-V_{\infty} \cos \theta\right)+\beta V_{\infty} \sin \theta\right]
$$

where the multiplying factor $\left(\rho / \rho_{\infty}\right)^{1 / 2}$ has been suggested by Ricou and Spalding (10) for plumes with $\rho / \rho_{w} \ll<1$.

The combustion model is based on the work of Magnussen and Hjertager (11). It relates the rate of combustion to the rate of dissipation of fuel and oxygen eddies and expresses the rate of reaction by the mean concentration of the reacting species, the turbulent kinetic energy and the rate of dissipation of this energy. An important feature is that this model differs from the eddy-break-up model in relating the dissipation of the eddies to the mean concentration, instead of the concentration fluctuations what is an obvious simplification. Consequently, the local rate of heat release can be expressed as :

$$
Q=C\left(Y_{F}, Y_{o x} / v\right) \Delta H_{c} \frac{\varepsilon}{k} \rho
$$

where $\mathbf{C}$ is an efficiency factor that takes into account the completeness of the combustion and the dimension of the combustible surface. Note that writing ( $Y_{F}$, $\left.Y_{o x} / v\right)$ means that, locally, the mean values of mass fractions $Y_{F}$ and $Y_{o x}$ are compared and that the lowest is rate determining.

For what concerns the radiative heat loss, it is assumed that the radiative heat transfer inside the flame is negligeable and that the transfer to the environment is essentially radial. Knowing that for most fuels only a fraction of the heat liberated in the flame is radiated to the environment and that the rest is entrained convectively in the buoyant plume, the heat loss is considered as a constant fraction (the radiative fraction $\mathrm{X}$ ) of the power generated in each control volume under consideration.

The different parameters required for the computation can be inferred from the experiments or a literature survey. The generally used values of entrainment parameters $(a=0,12$ and $\beta=0,1)$ are values proposed by a number of previous workers and tested with a wide range of applications. Only the efficiency factor has to be estimated, although, it is not an adjustable factor. As indicated above, it has a physical meaning and it is possible to assess a relevant value for each considered situation.

\section{2/ Ceiling Impingement Region}

This region can be considered as a control volume located at the impingement of an oblique jet on a flat wall (see Fig. 1). It is assumed that the back ward and forward layers formed along the ceiling are well stratified and flow predominantly in $\mathrm{x}$ direction (possible crossflow-swirl are neglected). Thus, a tunnel/ceiling width is not introduced in the analysis and the conservation equations are written as :

- Conservation of mass :

$$
e_{f} \rho_{f} v_{f}+e_{b} \rho_{b} v_{b}=2 r_{p} \rho_{p} v_{p}
$$

- Conservation of horizontal momentum : 
$e_{f} \rho_{f} v_{f}^{2}-e_{b} \rho_{b} v_{b}^{2}=2 r_{p} \rho_{p} v_{p}^{2} \cos \theta$

- Conservation of energy :

$$
q_{r_{c}}^{\cdot}+e_{f} \rho_{f} v_{f} C_{p} \int_{T_{\infty}}^{T_{f}} d T+e_{b} \rho_{b} v_{b} C_{p} \int_{T_{\infty}}^{T_{b}} d T=2 r_{p} \rho_{p} v_{p} C_{p} \int_{T_{\infty}}^{T_{p}} d T
$$

Even if at a distance for away from the stagnation point $v_{f}=v_{b}=v_{p}$, to facilitate the analysis of situations in which the smoke layer inlet velocity is different from the impinging-jet velocity, a proportionality factor $0<\mathbf{k}_{\mathbf{v}}<1$, as suggested by Hwang et al. (5) is introduced:

$$
v_{f}=v_{b}=k_{v} v_{p}
$$

Furthermore, an additional equation must be added to take in to account the heat transfer from the gas layer to the ceiling wall. The corresponding expression depends on the considered ceiling wall configuration : finite-thickness slab or semi-infinite wall. In fact, since semi-infinite configuration does not allow for steady-state solutions, the finite-thickness slab modelling is chosen with inner face exposed to steady radiant and convective heating and outer face to convective cooling.

The combination of the different equations permits one to obtain the inlet velocity, temperature and density for the ceiling smoke layers, as well as their thicknesses. These are given by:

$$
e_{b}=\frac{\rho_{p} r_{p}}{k_{v} p_{b}}\left(1+\frac{\cos \theta}{k_{v}}\right) \quad e_{f}=\frac{\rho_{p} r_{p}}{k_{v} \rho_{b}}\left(1-\frac{\cos \theta}{k_{v}}\right)
$$

\section{3/ Reverse Layer Modelling}

The analysis is closely related to the analysis of Hwang et al. (5) and its main features are only briefly reported here. The conservation equations for the control volume (see Fig. 1) are expressed as follows :

- Conservation of mass :

$$
\frac{d}{d x}\left(e_{b} \rho_{b} v_{b}\right)=E_{b} \rho_{\infty}\left(v_{b}+V_{\infty}\right)
$$

where $E_{b}$ is an entrainment coefficient deduced from the data of Ellison and Turner (12).

$$
E_{b}=E_{b} \exp \left(-5 \cdot \frac{g\left(\rho_{\infty}-\rho_{b}\right) e_{b}}{\mathrm{p}_{\infty}\left(v_{\infty}+v_{b}\right)^{2}}\right)
$$

the term of the exponential factor being the local Richardson number.

- Conservation of momentum : 
Bakke and Leach (13) have suggested an expression that can be applied in this problem :

$$
\frac{d}{d x}\left(\rho_{b} v_{b}^{2} e_{b}\right)+V_{\infty} E_{b} \rho_{\infty}\left(v_{b}+V_{\infty}\right)=-\frac{d p}{d x} e_{b}-\tau_{s}-\tau_{c}-\frac{d}{d x}\left(g\left(\rho_{\infty}-\rho_{b}\right) \frac{e_{b}^{2}}{2}\right)
$$

where $d p / d x$ is the pressure drop in the flow and $t_{g}$ and $\tau_{c}$ respectively the shear stress at the interface smoke-air and at the ceiling in the smoke layer.

- Conservation of energy :

$$
\frac{d}{d x}\left(\rho_{b} v_{b} C_{p} T_{b} e_{b}\right)-C_{p} T_{\infty} E_{b} \rho_{\infty}\left(v_{b}+V_{\infty}\right)=-q_{r_{c}}
$$

To facilitate the analysis, the velocity and density profiles are taken to be uniform across the smoke layer. Moreover, it is assumed that the specific heat $\mathrm{Cp}$ of the combustion products and the air is the same. Then, the equations of conservation can be restructured by introducing the Reynolds analogy between heat transfer and fluid friction and by replacing $\left(-\tau_{s}-(d p / d x) e_{b}\right)$ by the wall shear stress in the main flow and rearranged in nondimensional form. A more detail description of all these transformations is given in the Ref (5).

The temperature along the ceiling tends to lessen when the distance of the plume impact point increases. To accomodate the situation, the ceiling, modelled as said above as a finite-thickness slab, can be represented by a series of sections, each of length $\mathrm{dx}$. If we consider, in a given section, a slice of thickness $\mathrm{K} . \Delta z$, assumed to be isothermal ( $\mathrm{K}$ within $1 \%$ is appropriate), and located on the next step of the numerical integration, then the steady-state heat balance can be written:

$$
-K \Delta z \lambda \frac{d^{2} T_{c}}{d x^{2}}+h_{i}\left(T_{c}-T_{b}\right)+\frac{1}{\frac{1}{h_{o}}+\frac{(1-K) \Delta z}{\lambda}}\left(T_{c}-T_{\infty}\right)=0
$$

If ho is assumed constant and taken as a coefficient for a natural convection above the ceiling, the problem can be solved explicitely by setting $: h_{i_{n}}=h_{i_{n-1}}$ (inner coefficient calculated by introducing Reynolds analogy), and $T_{b_{n}}=T_{b_{3 \cdot 1}}$ (temperature of the reverse layer calculated on the preceding integration step, the initial condition being the temperature calculated in the turning region). Nute that to determine the condition for which the back layer ceases to exist, a simple mathematical argument, deduced from the conservation equations governing this layer, can be used (see Ref. 5). This condition is equivalent to have the dimensionless Richardson number equal to:

$$
\frac{p_{b}}{p_{\infty}}\left(\frac{v_{b} / V_{\infty}}{1+v_{b} / V_{\infty}}\right)^{2}
$$

\section{VALIDATION OF THE MODEL}

\section{1/ Validation on a Small-scale Experiment}

The small-scale experiment used to validate the model results has already 
been described in a previous work (6). It is made of a shell of glass, $0.95 \mathrm{~cm}$ thick, in half-cylinder form picturing an arched tunnel with an inside diameter of $30 \mathrm{~cm}$ and $300 \mathrm{~cm}$ in length (Figure 2). The heat source is a small porous burner, $2 \mathrm{~cm}$ in diameter, located in the middle of the tunnel in its median plane. The supply rate, regulated by a rotameter calibrated for the operational conditions, is variable, permitting to carry out tests with different powers. The ventilation flow is obtained with a fan having variable rotation speed, placed at one end of the tunnel and working by extraction. The ventilation velocity measurements are carried out with an anemometric probe.

The measurements of the length of the reverse layer is made by means of a low power laser beam directed in the median plan of the tunnel, just under the ceiling. The particles present in the smoke play the role of tracer by scattering and made the beam visible permitting one the visual measurement. Despite the semicylindrical geometry involved, the two-dimensional analysis with the finitethickness slab appears suitable to simulate the flow which is actually threedimensional. The smoke flow being very turbulent in the turning region, the correlation of forced convection for horizontal surface has been employed at the inner face. In contrast, the correlation of natural convection has been used at the

TABLE 1. Characteristics of the small-scale experiments

\begin{tabular}{|c|c|}
\hline Rate of heat release & $\begin{array}{l}\text { Imposed and variable } \\
\text { between } 560 \text { and } 1300 \mathrm{~W}\end{array}$ \\
\hline $\begin{array}{c}\text { Mass stoichiometric air to propane } \\
\text { ratio } v\end{array}$ & 15,6 \\
\hline Efficiency factor $\mathrm{C}$ & 0,95 \\
\hline $\begin{array}{l}\text { Visual estima te of average flame } \\
\text { extent along the inclination axis }\end{array}$ & $\simeq 0,14 \mathrm{~m}$ \\
\hline Ventilation velocity $V_{\infty}$ & 0,19 and $0,21 \mathrm{~m} . \mathrm{s}^{-1}$ \\
\hline $\begin{array}{l}\text { Visual estimate of average angle of } \\
\text { deflection of the flame } \theta\end{array}$ & variable around $30^{\circ}$ \\
\hline $\begin{array}{l}\text { Radiative fraction } \mathrm{X} \\
\text { (measured in situ) }\end{array}$ & 0,4 \\
\hline Temperature at the base of the burner & $600 \mathrm{~K}$ \\
\hline Tunnel radius & $0,15 \mathrm{~m}$ \\
\hline Shell of glass thickness & $0,0095 \mathrm{~m}$ \\
\hline Glass conductivity & $1,2 \mathrm{~W} \cdot \mathrm{m}^{-1} \cdot \mathrm{K}^{-1}$ \\
\hline Friction coefficient smoke-ceiling & 0,008 \\
\hline $\begin{array}{c}\text { Friction coefficient smoke-ventilation } \\
\text { current }\end{array}$ & 0,003 \\
\hline $\begin{array}{l}\text { Proportionality factor between plume } \\
\text { and backlayer inlet velocities } k\end{array}$ & 0,3 \\
\hline $\begin{array}{l}\text { Preexponential factor } \mathrm{E}_{\mathrm{b}_{\mathrm{u}}} \text { of the } \\
\text { entrainment coefficient }\end{array}$ & 0,023 \\
\hline
\end{tabular}




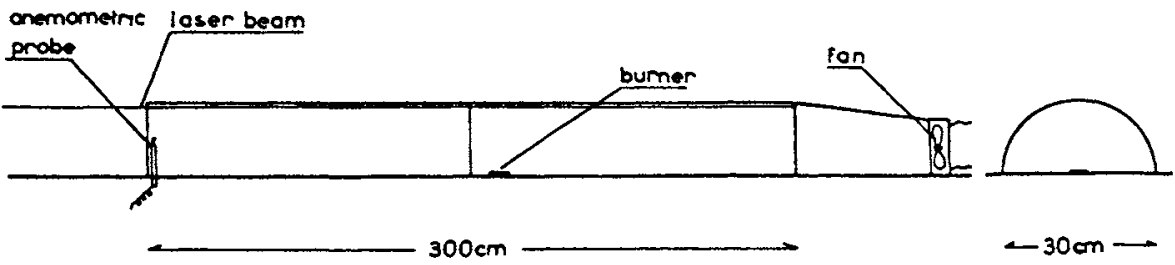

FIGURE 2 Schematic of the tunnel scale model

outer face. The model has been tested for different fire source powers and ventilation velocities. Table 1 shows the different parameters introduced in the successive stages of the small-scale simulation.

The reliability of the different parameters required by the fire plume model has been commented above. The value of the distribution factor $k_{\mathrm{v}}$ of velocities suggested by Hwang et al. (5) has been used and no further refinement of this value was attempted. The values of the friction coefficients adopted have been used in other works (13)(14). An interesting observation is that they exert relatively minor effects on the smoke layer length. This indicates that heat transfer considerations are not very important in the determination of the dynamics of the ceiling flow. Finally, the preexponential factor $E_{b_{0}}$ of the entrainment correlation was adjusted to match the experimental observation. It is really the single adjustable factor of the code, although it will not have a very noticeable effect. For comparison, the value reported by Hwang et al. (5) is 0,075 .

Figure 3 shows the evolution of the reverse layer length with the power of the fire source for two ventilation speeds. Overall, the agreement between

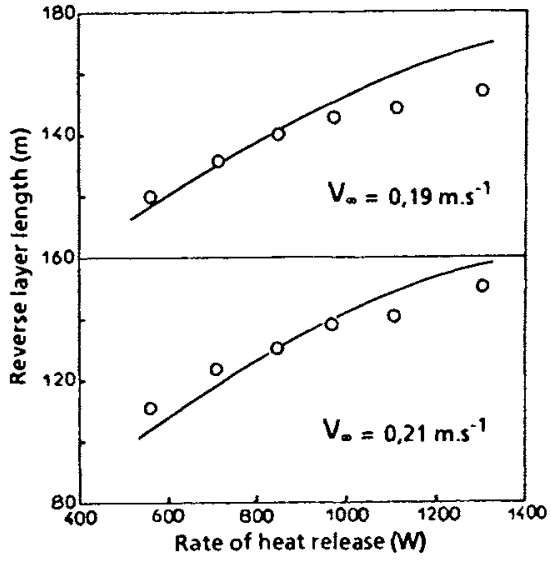

FIGURE 3 Evolution of reverse layer length as a function of the rate of heat release for different ventilation speeds. Small-scale experiment (calculation :-; measurement : o)

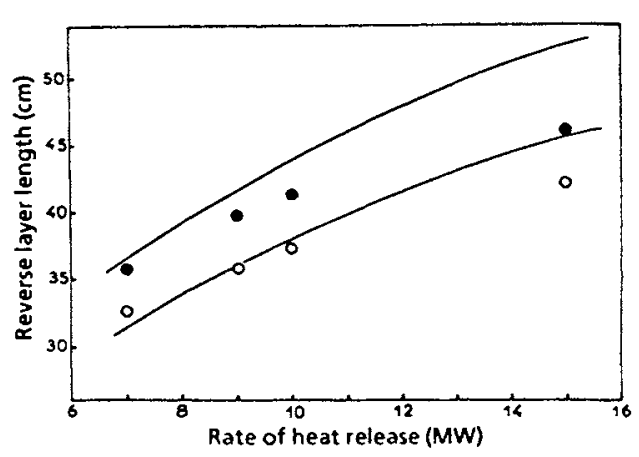

FIGURE 4 Evolution of reverse layer length as a function of rate of heat release for different ventilation speeds. Application to Paris metro tunnel (calculation:-; deduced from scaling procedure : $\mathrm{o}\left[\mathrm{V}_{\infty}=2 \mathrm{~m} \cdot \mathrm{s}^{-1}\right]$, - $\left[\mathrm{V}_{\infty}=1,8 \mathrm{~m} \cdot \mathrm{s}^{-1}\right]$ 
calculation and measurement is reasonably good. Experimental results as well as calculation exhibit that, for a given ventilation speed, the length of the backlayer increases with the rate of heat release, but that the curves bend due to the simultaneous increase of shear stress and re-entrainment at the interface between smoke and fresh air. The larger is the ventilation speed, the more difficult it becomes to diminish the extent of the layer.

It should be noted however that the model slightly overestimates the lengths. The main reason seems to be the assumption of uniform profiles, made to simplify the analysis. In fact, one important characteristic of the smoke backflow is its pronounced stratification with very marked gradients of temperature and velocity. As one might expect, larger values of the velocity have repercusion on Rich ardson number and entrainment, and in turn on the smoke extent.

\section{2/ Application to a Real Situation (Paris Metro Tunnel)}

Despite the lack of experimental data, the model has been applied to a real situation while refering to the simple scale modelling procedure that we have proposed previously (6). Fires in metro cars occur more often accidentally (heating of pneumatic bearings, discarding of cigarettes, etc.) or sometimes as a result of arson. Thus, their development is uncertain, and a function of the nature of the combustible materials, of the ventilation conditions, etc. . This explains why the order of magnitude of the rates of heat release generally reported can be very variable : basically between 5 and $15 \mathrm{MW}$ (15).

TABLE 2. Characteristics of the large-scale simulation

\begin{tabular}{|c|c|}
\hline Rate of heat release & Variable between 7 and $15 \mathrm{MW}$ \\
\hline $\begin{array}{c}\text { Mass stoichiometric air to fuel } \\
\text { ratio } v\end{array}$ & 14,7 \\
\hline Efficiency factor $\mathrm{C}$ & 0,4 \\
\hline $\begin{array}{l}\text { Estimate of ayerage flame extent along } \\
\text { the inclination axis }\end{array}$ & $\approx 4,5 \mathrm{~m}$ \\
\hline Ventilation velocity & 0,8 and $2 \mathrm{~ms}^{-1}$ \\
\hline $\begin{array}{c}\text { Estimate of average angle of deflection } \\
\text { of the flame } \theta \text { (from the empirical } \\
\text { correlation proposed by Pipkin and } \\
\text { Sliepcevich (16)) }\end{array}$ & between 45 and $60^{\circ}$ \\
\hline Radiative fraction $\mathrm{X}$ & 0,3 \\
\hline Surface temperature of fuel & $493 \mathrm{~K}$ \\
\hline Tunnel radius & $4,7 \mathrm{~m}$ \\
\hline Ceiling thickness & $10 \mathrm{~m}$ \\
\hline Ceiling thermal conductivity & $1 \mathrm{~W} \mathrm{~m}^{-1} \mathrm{~K}^{-1}$ \\
\hline $\begin{array}{c}\text { The values of the different parameters } \\
\text { introduced in the step of reverse layer } \\
\text { modelling are the same than afore- } \\
\text { mentioned }\end{array}$ & \\
\hline
\end{tabular}


The full-scale reference chosen being the Paris metro (tunnel in arched section form of mean radius $4,7 \mathrm{~m}$ ), a Richardson modelling procedure (6) shows that on the basis of the respective values of power and dimension for this full-scale reference and for the small-scale experiment, the ventilation speeds applied at small-scale (around $0,2 \mathrm{~ms}^{-1}$ ) correspond to ventilation speeds ranging between about 1,8 and $2 \mathrm{~ms}^{-1}$. These values are quite acceptable compared with the ventilation speeds known as "de comfort" (around $2 \mathrm{~ms}^{-1}$ ), generally applied in the underground railway networks. Thus, it is possible to correlate the responses of the two systems to equivalent phenomena.

The problem is also treated with the plane finite-thickness slab assumption. It should be better to consider the boundary material of the tunnel as a semiinfinite wall but, as stated above, this modelling does not allow for steady state heat balance. Anyhow, the ceiling is thick enough to present a thermal resistivity which minimizes heat loss.

For convenience, the fire source is simulated by a pool fire of kerosene. Table 2 shows the different parameters introduced in the successive stages of the large-scale simulation.

Figure 4 shows the evolution of the reverse layer length with the power of the fire source for two ventilation speeds. The similarity being preserved for small and full scale systems a comparison is also made with the prediction deduced from the simple scaling law proposed previously (6). The simulation appears only approximate but it can be justified only through the comparison with a simple scaling law. Further validation, on the basis of large-scale experiments is required to provide more confidence in the prediction.

\section{CONCLUDING REMARK}

The model presented here, though two-dimensional, appears to offer a good description of the complex phenomenon of smoke backflow in a tunnel fire situation, as a function of ventilation speed and power source. Despite the lack of full-scale experimental data, the agreement observed between the calculated results and the prediction by means of a scale modelling procedure suggests its predictive applicability. The ease of implementation and the low computational time make this model particularly appropriate for live safety studies.

It appears that the dynamic of the reverse flow does not depend strongly on the consideration of heat loss to the ceiling. Another outstanding inference is that the reverse layer length is a strong function of the ventilation speed in comparison with the power source. Results show also clearly some weakness of the model. For high fire source power it tends to overestimate the length of the reverse flow. This is essentially due to the fact that the entrainment law adopted to characterise the relative velocity between the smoke layer and the ventilation current is no more suitable. Refinements of this problem could be envisaged. Modification could be also envisaged to obtain more realistic profiles than "top hat" profiles, as well in the plume as in the reverse layer.

\section{REFERENCES}

1. Eisner, M.S. and Smith, P.B., "Convection Effects from Underground Fires : The Backing of Smoke Against the Ventilation", Safety in Mines Research Establishment, Research Report, $n^{\circ} 96,1954$.

2. Thomas, P.H., "The Movement of Buoyant Fluid Against a Stream and the Venting of Underground Fires", Fire Research Note 351/1958, Fire Research Station, Borehamwood, Herts, England, 1958. 
3. Thomas, P.H., "The Movement of Smoke in Horizontal Passages Against an Air Flow", Fire Research Note $723 / 1968$, Fire Research Station, Borehamwood, Herts, England, 1968.

4. De Ris, J., "Duct Fires", Combustion Science and Technology : vol. 2, 239. $258,1970$.

5. Hwang, C.C., Chaiken, R.F., Singer, J.M. and Chi, D.N.H., "Reverse Stratified Flow in Duct Fires : A Two-dimensional Approach", Sixteenth Symposium (International) on Combustion, The Combustion Institute, Pittsburgh, 1385-1395, 1977.

6. Vantelon, J.P., Guelzim, A., Quach, D., Doan Kim Son, Gabay, D. and Dallest, D., "Investigation of Fire-induced Smoke Movement in Tunnels and Stations : An Application to the Paris Metro", Fire Safety Science, Proceedings of the Third Symposium, 907-918, 1991.

7. Guelzim, A., Souil, J.M., Vantelon, J.P. and Borner, J.P., "Flame Radiation From Pool Fires Tilted by Wind", Interflan'93, Proceedings, 121-131, 1993.

8. Hoult, D.P., Fay, J.A. and Forney, L.J., "A Theory of Plume Rise Compared with Field Observations", J. Air Pollut. Control Assoc. : 19 (n $\left.{ }^{\circ} 8\right), 585-590$, 1969.

9. Fay, J.A., Escudier, M.P. and Hoult, D.P., "A Correlation of Field Observations of Plume Rise", J. Air Pollut. Control Assoc. : 20, 391, 1970.

10. Ricou, J.P. and Spalding, D.B., "Measurement of Entrainment by Axisymmetrical Turbulent Jets", J. Fluid Mech. : 9, 21-32, 1961.

11. Magnussen, B.F. and Hjertager, B.H., "On Mathematical Modelling of Turbulent Combustion with Special Emphasis on Soot Formation and Combustion", Sixteenth Symposium (International) on Combustion, The Combustion Institute, 719-729, 1976.

12. Ellison, T.H. and Turner, J.S., "Turbulent Entrainment in Stratified Flows", J. Fluid Mech. : 6, 423, 1959.

13. Bakke, P. and Leach, S.J., "Turbulent Diffusion of a Buoyant Layer at a Wall", J. Appl. Sci. Res. : Sec. A, 15, 97, 1965.

14. Escudier, M.P., "Aerodynamics of a Burning Turbulent Gas Jet in a Crossflow", Combustion Science and 'Technology : 4, 293-301, 1972.

15. Curtat, M., Private communication, Centre Scientifique et Technique du Bâtiment, France, 1992.

16. Pipkin, O.A. and Sliepcevich, C.M., "Effect of Wind on Buoyant Diffusion Flames", I\&EC Fundamentals : $3, n^{\circ} 2,147-154,1964$. 